\title{
CONTRole da Mistura Ar/COMbustível EM Um Motor a COMbustão INTERNA: SiSTEMA EM MALHA FECHADA
}

\author{
Bruno Silva Pereira, João Francisco Justo e Armando Antonio Maria Laganá \\ Escola Politécnica da Universidade de São Paulo \\ E-mail: bruno.sp@usp.br, jjusto@1me.usp.br, lagana@1si.usp.br
}

\section{RESUMO}

O controle da mistura ar/combustível é muito importante para o correto funcionamento dos motores à combustão interna ciclo Otto. A relação entre o ar e o combustível influencia diretamente no funcionamento do motor, na emissão de poluentes e no consumo de combustível. Este trabalho apresenta o desenvolvimento de um controle da mistura ar/combustível a partir do estudo de modelos de malha fechada deste sistema. Esse controle tem por objetivo manter a mistura o mais próxima possível do ponto estequiométrico, a fim de otimizar a taxa de conversão de gases poluentes pelo catalisador, e utiliza um sensor de oxigênio, conhecido como sonda lambda, para realizar a realimentação do sistema, indicando se a mistura está no ponto estequiométrico. Este trabalho também apresenta o desenvolvimento de um compensador em malha fechada para controlar a mistura a/c (ar/combustível) em outros pontos, além do estequiométrico, através do uso de uma sonda lambda de banda larga.

\section{INTRODUÇÃO}

Nos últimos 40 anos, a popularização da eletrônica, com a utilização de circuitos integrados cada vez menores e mais confiáveis, culminou com sua introdução na indústria automobilística. Isso possibilitou o surgimento de novas tecnologias automotivas, particularmente associadas à substituição de elementos mecânicos por eletrônicos, levando a uma melhoria no desempenho e confiabilidade dos veículos [1,2]. Além disso, a introdução de novas legislações sobre a emissão de poluentes e a necessidade da redução da demanda energética utilizada pelos veículos requerem o desenvolvimento de novas tecnologias $[3,4]$.

As inovações na tecnologia embarcada nos veículos, para gerenciamento dos motores, estão basicamente no controle da mistura ar/combustível, acelerador eletrônico, marcha lenta, ignição e detonação, e controle para veículos de flex-fuel e híbridos (motor à combustão e elétrico), além de avanços na detecção de falhas. Há também muitas inovações na área de transmissão do veículo, com a introdução de câmbios automáticos e semi-automáticos. Nas áreas de conforto e segurança, existe uma série de sistemas de controle, como o de freios ABS (Anti-lock brake system), estabilidade, suspensão ativa e de tração [5, 6]. Além disso, houve uma grande inovação na forma como os sistemas automotivos são desenvolvidos pela introdução de softwares com o conceito de desenvolvimento baseado em modelos, que visam melhorar a eficiência do projeto minimizando o número de testes práticos realizados a partir do uso de simulações [7]. 
Especificamente no controle da mistura ar/combustível, existe uma série de estratégias utilizando as mais variadas técnicas como, por exemplo, técnicas de controle adaptativo, robusto, ótimo, dentre outros [8]. Esta relação da mistura entre ar e combustível está ligada diretamente ao desempenho, às emissões de poluentes e consumo de combustível nos motores à combustão interna $[9,8]$. Assim, através das técnicas de controle, como as descritas neste trabalho, é possível fazer com que o sistema a atinja um objetivo de desempenho e confiabilidade.

\section{INTRODUÇÃO TEÓRICA}

O funcionamento correto do motor requer um cuidadoso gerenciamento, que é basicamente dividido em três sistemas: os sistemas de admissão de ar, de combustível e de ignição. Há algumas décadas, esses sistemas eram todos controlados por componentes mecânicos e elétricos, porém atualmente são gerenciados totalmente por componentes eletrônicos, através de sensores e atuadores. A figura 1 mostra os elementos fundamentais do gerenciamento eletrônico do motor.

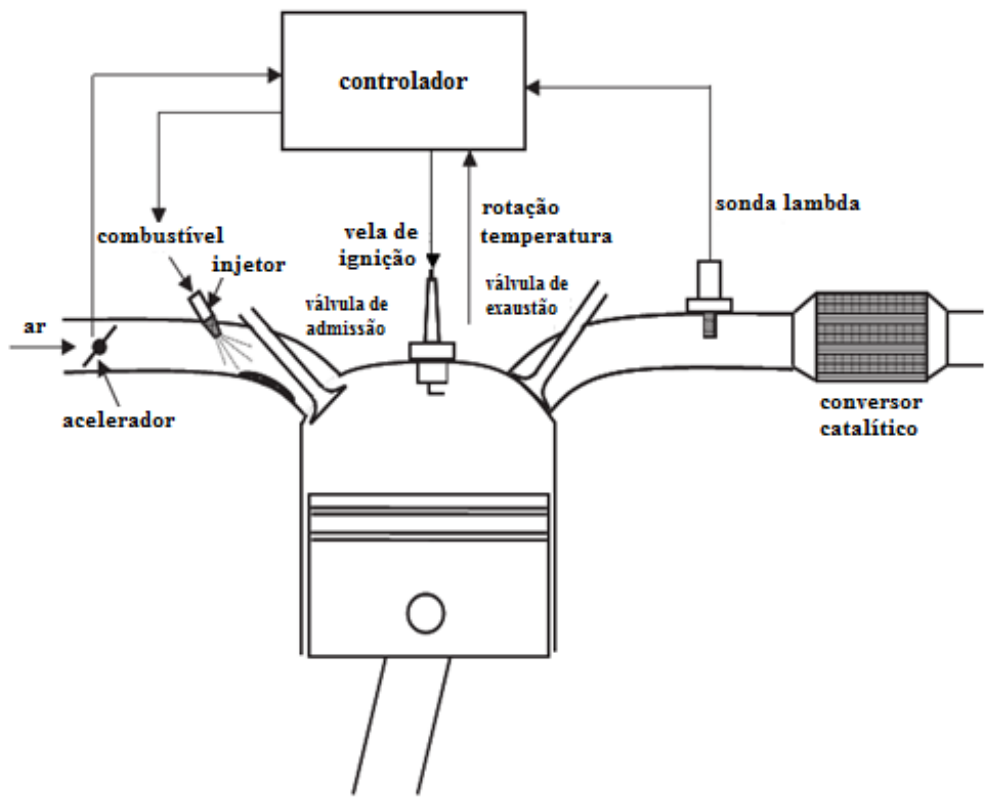

Figura 1 - Sistema de gerenciamento do motor [10].

O sistema de admissão de ar é o responsável por dosar a quantidade de ar admitido nos cilindros. Esta dosagem é efetuada por um corpo de borboleta que restringe ou libera a passagem de ar através de sua abertura, sendo que quanto maior a vazão de ar admitido nos cilindros maior será o trabalho e o torque efetuados pelo motor. Quando o motorista demanda uma grande aceleração no pedal acelerador, a válvula borboleta efetua uma abertura que irá garantir o torque necessário para atender à demanda exigida.

O sistema de combustível se encarrega de calcular a quantidade necessária de combustível a ser injetado no motor, para seguir a demanda de aceleração do motorista. Esse sistema utiliza sensores para calcular a massa de ar que está sendo admitida nos cilindros e, assim, calcular a quantidade exata de combustível que deve ser injetada através dos bicos injetores $[11,12]$. Alguns sensores são utilizados como realimentação destes sistemas para corrigir alguns 
parâmetros, como, por exemplo, o sensor lambda, que é utilizado para realizar o controle em malha fechada da mistura entre ar e combustível admitida no motor.

O sistema de ignição é responsável por gerar a centelha na câmara de combustão do motor, através das bobinas e velas de ignição. A ignição da mistura é um fator muito importante no funcionamento do motor, pois influencia diretamente na combustão e consequentemente no torque gerado pelo motor. Assim, o controle da ignição atua para que a centelha ocorra de forma a garantir que a combustão irá resultar no torque exigido [13].

Estes três sistemas precisam funcionar corretamente para que se possa alcançar o melhor desempenho do veículo e também garantir que o veículo emita a menor quantidade de poluentes possível. Atualmente, para diminuir a emissão de poluentes é indispensável o uso de componentes para realizar o pós-tratamento dos gases de escape. Esses componentes, chamados de conversores catalíticos, tem por objetivo realizar a redução dos poluentes até um limite imposto pelas legislações.

\subsection{Relação ar/combustível}

A relação ar/combustível tem grande importância no controle de motores à combustão interna. Esta relação é dada pela massa de combustível necessária para que a combustão com uma dada quantidade de ar seja estequiométrica. A estequiometria é importante na combustão, pois significa que toda a massa de combustível que entrou no cilindro foi consumida, ou mais especificamente, todos os hidrocarbonetos foram convertidos, juntamente com o oxigênio, em $\mathrm{H}_{2} \mathrm{O}$ (água) e $\mathrm{CO}_{2}$ (dióxido de carbono) em uma combustão ideal [14]. Sabendo-se a razão estequiométrica do combustível utilizado, é possível definir o coeficiente lambda ( $\lambda$ ) [13]:

$\lambda=\frac{\text { mistura } \mathrm{a} / \mathrm{c} \text { atual }}{\text { mistura } \mathrm{a} / \mathrm{c} \text { estequiométrica }}$

O coeficiente lambda é utilizado para se determinar qual o estado da mistura que o motor consumiu. Quando o coeficiente lambda é menor do que $1(\lambda<1)$, a mistura é denominada rica, significando que a mistura atual possui mais combustível do que a quantidade ideal para que o oxigênio possa consumi-lo, sendo que a parcela não consumida será perdida. Por outro lado, quando lambda é maior do que $1(\lambda>1)$, a mistura é denominada pobre, ou seja, a mistura atual possui uma quantidade maior de oxigênio do que a ideal para consumir o combustível. Idealmente tem-se lambda igual a $1(\lambda=1)$, quando a mistura atual é exatamente igual à mistura ideal, isto é, toda a mistura foi convertida [12].

O valor da relação lambda impacta diretamente o funcionamento do motor, principalmente na potência entregue ao veículo. Além disso, o consumo de combustível e a emissão de poluentes também estão diretamente ligados ao valor do coeficiente. A figura 2 mostra a relação entre o fator lambda e a potência e consumo de combustível. 


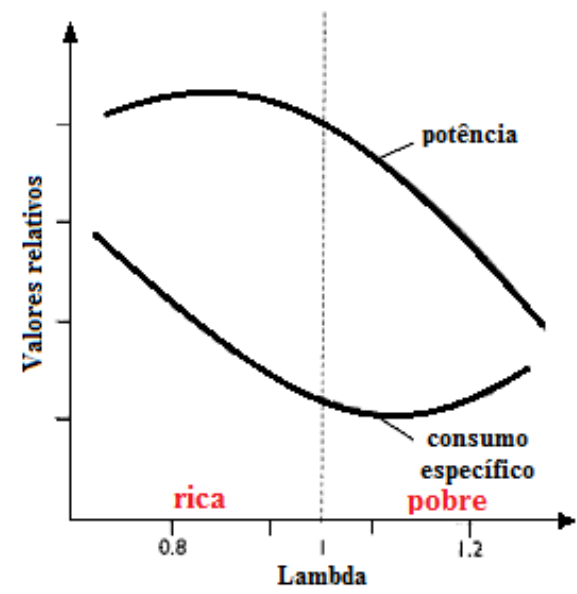

Figura 2 - Relação de lambda com potência e consumo de combustível [13].

Quando lambda é maior do que 1, a mistura se torna pobre, o que resulta em uma diminuição na potência do motor, pois como a mistura tem menos combustível do que ar em relação ao ideal, a pressão de combustão diminui, fazendo com que a potência e, consequentemente, o torque e o consumo de combustível também diminuam. $\mathrm{Na}$ condição de mistura pobre também podem ocorrer falhas na combustão fazendo com que a mistura não queime. Esse fenômeno é conhecido como misfire [8].

Na condição de estequiometria, a potência e o consumo são maiores do que em mistura pobre, pois se tem maior pressão de combustão e mais injeção de combustível. Embora esta condição tenha um bom compromisso entre o consumo e a potência, enriquecendo a mistura, é possível obter maior potência, porém tendo um aumento no consumo. Entretanto, há um desperdício de parte do combustível injetado $[11,15]$.

\subsection{Emissão de poluentes}

A emissão de poluentes também está diretamente ligada ao valor de lambda, e foi a partir desta ligação que surgiu a necessidade de controlar a mistura ar/combustível. As emissões de poluentes podem ser reduzidas com o uso de conversores catalíticos, mas eles dependem diretamente do valor de lambda para funcionar corretamente. A figura 3 mostra a comparação da emissão dos gases poluentes $\mathrm{CO}$ (monóxido de carbono), $\mathrm{HC}$ (hidrocarbonetos) e $\mathrm{NO}_{\mathrm{x}}$ (óxidos de nitrogênio), que são os principais gases formados no processo de combustão e estão relacionados a lambda.

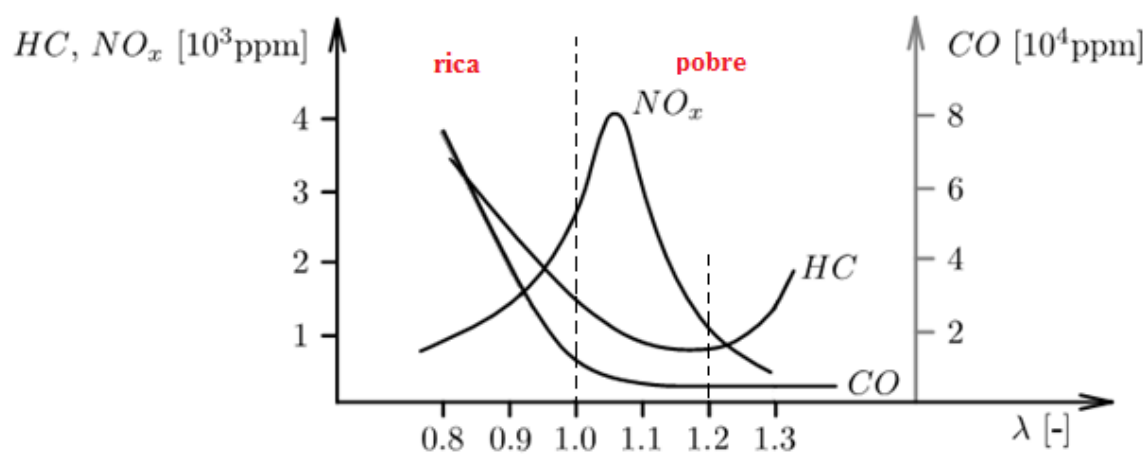

Figura 3 - Relação de lambda e a emissão de poluentes em partes por milhão (ppm) [8]. 
Atualmente, os veículos precisam controlar as emissões de gases poluentes expelidos pelo escapamento. Existem limites máximos estabelecidos por agências ambientais governamentais para a emissão dos poluentes $\mathrm{NO}_{\mathrm{x}}, \mathrm{HC}$ e $\mathrm{CO}$. Para atender às legislações ambientais, é utilizado um conversor catalítico que faz basicamente a conversão dos gases poluentes em substâncias não poluentes. As principais conversões são $[16,17]$ :

- $\quad$ Oxidação de hidrocarbonetos em dióxido de carbono e água;

- Oxidação de monóxido de carbono em dióxido de carbono; e

- $\quad$ A redução de $\mathrm{NO}_{\mathrm{x}}$ em nitrogênio e oxigênio.

A eficiência do catalisador depende principalmente da relação ar/combustível, porém, como apresentado na figura 4, o valor da relação entre a eficiência de conversão e lambda para a máxima eficiência de conversão dos três gases não é a mesma [8].

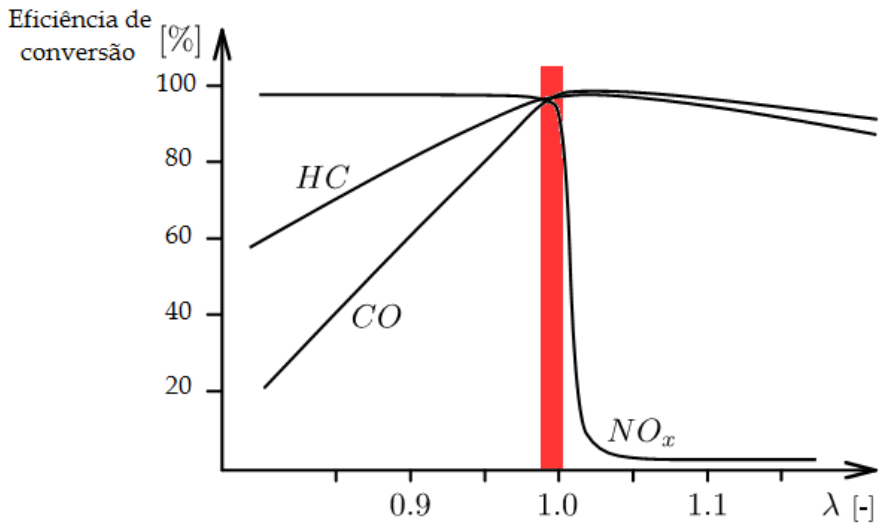

Figura 4 - Taxa de conversão catalítica em relação à relação a/c [8].

Existe uma janela na relação a/c (em destaque em vermelho na figura 4) em torno do ponto estequiométrico (de aproximadamente 14,7 para gasolina), com maior área na parte rica, onde é possível obter uma eficiência aceitável para converter os três gases e ficar dentro dos limites estabelecidos pelas legislações. Esta janela tem largura de aproximadamente $\pm 0,5 \%$ da relação ao valor estequiométrico, ou seja, entre 14,62 a 14,77, no caso da gasolina $[12,1]$. Para manter a relação dentro desta janela, é necessário o uso de um sistema eletrônico capaz de controlar e regular precisamente a quantidade de combustível e ar admitidos no motor.

\section{METODOLOGIA}

Primeiro foi definido um modelo para ser trabalhado o projeto de controle. O modelo escolhido é de um sistema de primeira ordem com um tempo morto, que é um modelo simplificado bastante comum para a representação do sistema da mistura ar/combustível, como mostra a figura 5: 


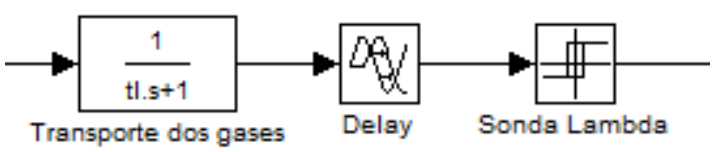

Figura 5 - Modelo da mistura ar/combustível.

Sendo que tl é o tempo de resposta do sistema e é dado por:

$\mathrm{tl}=\frac{2(\mathrm{Cil}-1)}{\mathrm{n} * \mathrm{Cil}}$

onde, Cil, é o número de cilindros do motor, e n é a velocidade de rotação do motor por segundo. $\mathrm{O}$ delay é aproximado por 2 vezes o valor de tl.

Com o sistema em malha aberta é realizado o cálculo da massa de ar que entra nos cilindros através da estratégia speed density que se baseia na equação da lei dos gases ideais:

$\mathrm{PV}=\mathrm{m}_{\mathrm{a}} \mathrm{RT}$

onde $\mathrm{P}$ é a pressão absoluta em $\mathrm{kPa}$ do ar de admissão, $\mathrm{V}$ é o volume, $\mathrm{m}_{\mathrm{a}}$ é a massa de ar, $\mathrm{R}$ a constante universal dos gases e T a temperatura do ar de admissão em Kelvin. Sabendo-se a massa de ar é possível calcular a massa de combustível $\mathrm{m}_{\mathrm{c}}$ utilizando a relação estequiométrica do combustível utilizado:

$\mathrm{m}_{\mathrm{c}}=\frac{\mathrm{m}_{\mathrm{a}}}{\text { relação } \mathrm{a} / \mathrm{c}}$

\subsection{Aplicação}

O controlador desenvolvido neste trabalho foi aplicado em um motor através de uma unidade de controle. Esta unidade consiste de três microcontroladores que dividem as tarefas do controle do motor que são o de gerenciamento, sincronismo e comunicação e diagnose, como mostra o diagrama de blocos da unidade:

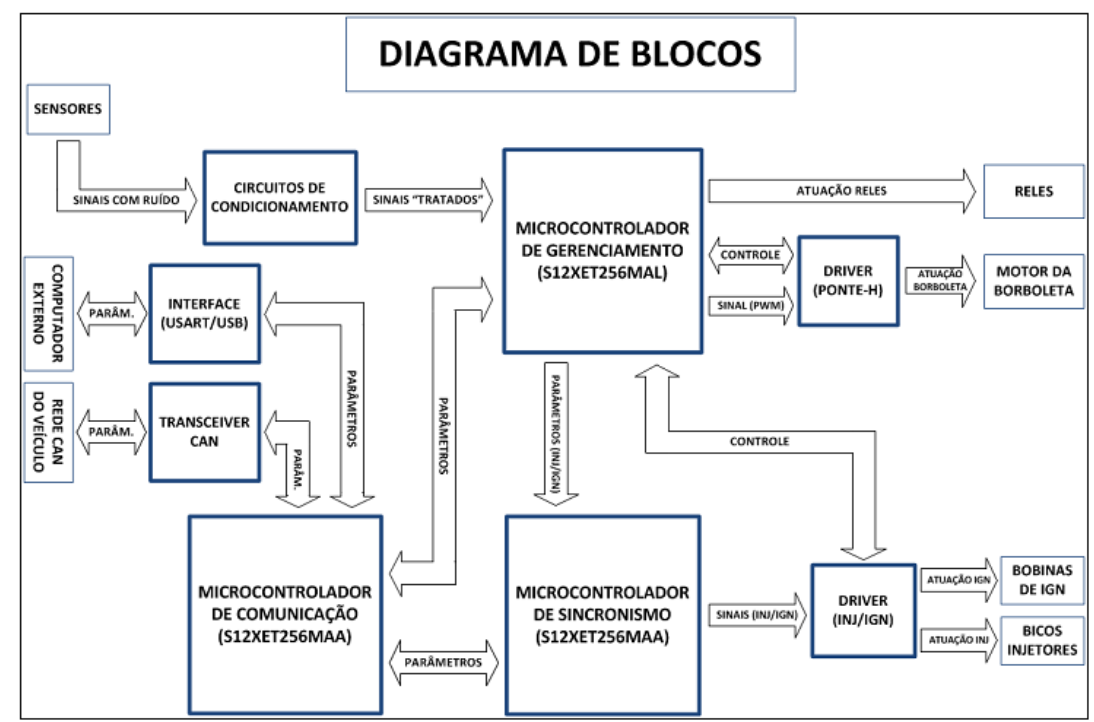

Figura 6 - Diagrama de blocos da unidade de controle [18]. 
Os microcontroladores utilizados na unidade são da linha automotiva S12 da Freescale $^{\mathrm{TM}}$ de 16 bits. Uma arquitetura descentralizada de blocos foi escolhida para dividir as tarefas de gerenciamento do motor e, assim, tornar o trabalho de programação dos microcontroladores menos complexo.

O bloco mais importante, o de gerenciamento, é responsável por ler e analisar os sinais de todos os sensores que estão acoplados ao motor do veículo. Com esses dados, o gerenciamento realiza os cálculos (cálculo da massa de ar e de combustível pela estratégia speed density) necessários para controlar o motor de acordo com a exigência de aceleração do motorista. O controle do motor é feito através da válvula borboleta, dos bicos injetores de combustível e das bobinas de ignição. O bloco de sincronismo é o responsável por efetuar os acionamentos dos bicos injetores de combustível e das bobinas de ignição, de acordo com os parâmetros passados pelo bloco de gerenciamento, de forma sincronizada com o motor, utilizando como base o sensor de rotação.

O bloco de comunicação é responsável por coletar as informações do gerenciamento e do sincronismo, a fim de disponibilizá-los (por uma conexão USB) para visualização em um computador. Ele também é responsável pela troca de informação com outros módulos do veículo através de uma rede CAN [18].

A sonda lambda usada para fazer as medições de lambda é a sonda de banda larga LSU4.2 da Bosch mais o medidor de lambda LA4 da ETAS.

Conforme descrito anteriormente, o projeto desenvolvido neste trabalho é aplicado em um motor através de uma unidade de gerenciamento eletrônico. Esta unidade é conectada ao veículo através de um sistema de interconexão conhecido como breakout box, que proporciona ao usuário verificar os sinais elétricos do veículo, dentre eles a leitura de sensores, além de possibilitar a introdução de novos sinais. A figura 7 mostra o compartimento do motor do veículo e também o sistema de interconexão que liga a ECU ao veículo.

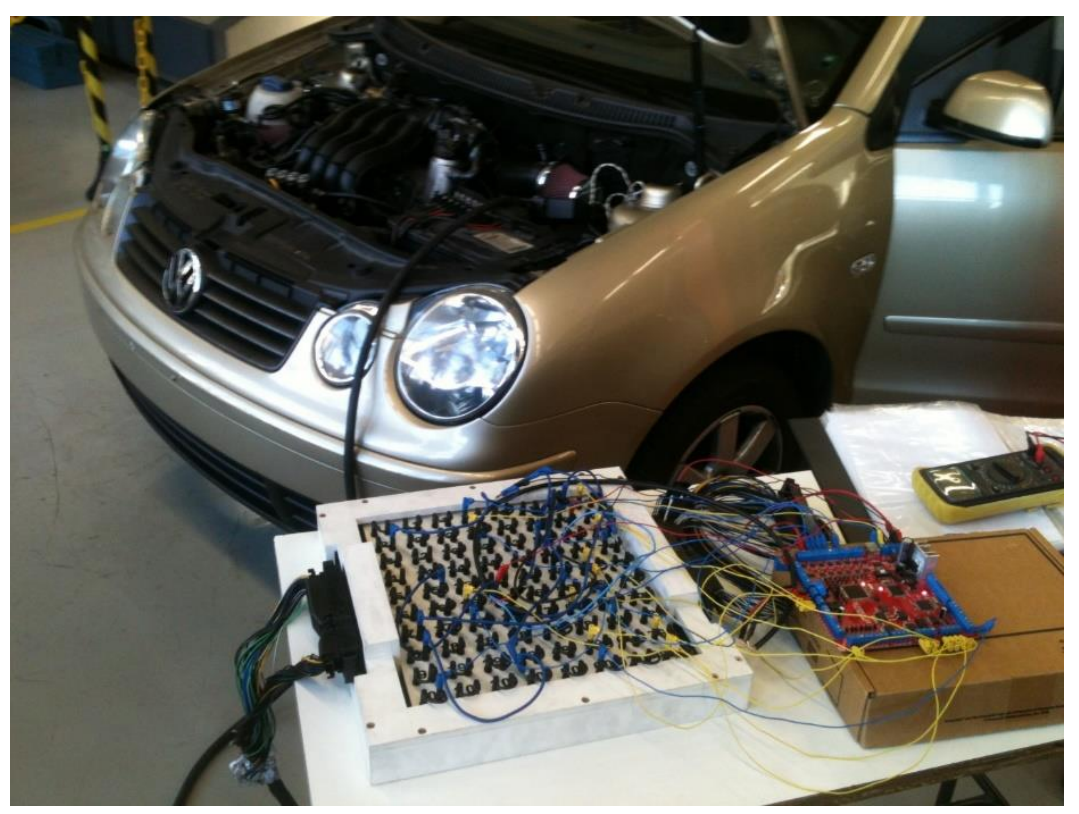

Figura 7 - Montagem prática: motor do veículo, sistema de interconexão e ECU. 


\section{PROJETO E RESULTADOS OBTIDOS}

Neste trabalho foram desenvolvidos dois controladores, um utilizando como realimentação o sinal do sensor lambda do tipo on-off e outro utilizando como realimentação o sinal do sensor de banda larga.

\subsection{Projeto utilizando a sonda lambda on-off}

O controlador C(s) em malha fechada recebe a realimentação do valor de lambda através de uma sonda lambda do tipo on-off e então atua com uma correção multiplicativa na massa de combustível calculada pela estratégia speed density para controlar o valor de lambda a fim de mantê-lo com um valor médio com um desvio menor do que $0,5 \%$ do valor estequiométrico. A figura 8 mostra o diagrama de blocos do sistema em malha fechada:

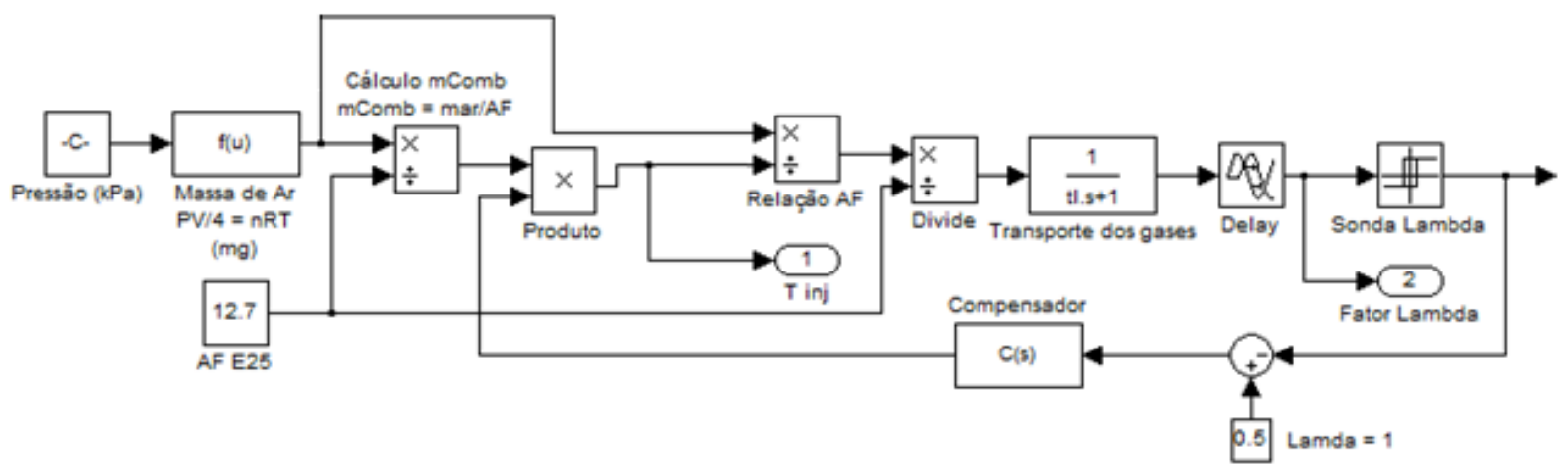

Figura 8 -Diagrama de blocos do sistema em malha fechada

O controlador escolhido foi do tipo PI (proporcional integral), que é um dos mais utilizados neste tipo de sistema, com a seguinte configuração:

$$
C(s)=1+\left(P+I \frac{1}{s}\right) e(t)
$$

Como o controlador deve ser implementado em um microcontrolador, o compensador foi transformado para sua forma no tempo discreto utilizando uma transformada $\mathrm{z}$ [19]. Assim, o integrador 1/s é aproximado pelo método de Euler (integração retangular) para $\mathrm{T}_{\mathrm{s}} /(\mathrm{z}-1)$ :

$\mathrm{C}(\mathrm{z})=1+\left(\mathrm{P}+\mathrm{IT}_{\mathrm{s}} \frac{1}{\mathrm{z}-1}\right) \mathrm{e}(\mathrm{z})$

$\mathrm{O}$ valor de I é escolhido como sendo igual ao valor do parâmetro $\mathrm{T}_{\mathrm{l}, \mathrm{e}}$ conforme a seção 2.5.2, e equação (15), para compensar o atraso do sistema, assim:

$\mathrm{I}=\mathrm{T}_{\mathrm{l}, \mathrm{e}}=\frac{2(\mathrm{Cil}-1)}{\mathrm{n} * \text { Cil }}=\frac{2(4-1)}{\mathrm{n} * 4}=\frac{3}{2 \mathrm{n}}$

O parâmetro constante $\mathrm{P}$ influencia diretamente no tempo de resposta do sistema e deve ter um valor pequeno para não causar uma variação muito grande em lambda e consequentemente criar uma perturbação na rotação no sistema real, e foi escolhido 
com o valor de 0,01 para garantir a estabilidade do sistema. $\mathrm{O}$ parâmetro $\mathrm{T}_{\mathrm{s}}$ é o intervalo de integração definido pelo tempo de um ciclo completo do motor dado por:

$\mathrm{T}_{\mathrm{s}}=\mathrm{T}_{\text {ciclo }}=\frac{120}{\mathrm{n}}$

onde n é a rotação do motor em RPM.

Com o controlador definido, foram realizadas algumas simulações para validação. $\mathrm{Na}$ primeira simulação, não foi aplicada nenhuma perturbação. A resposta do controlador $\mathrm{C}(\mathrm{z})$ varia conforme o sinal da sonda lambda muda de estado, conforme a figura 9.
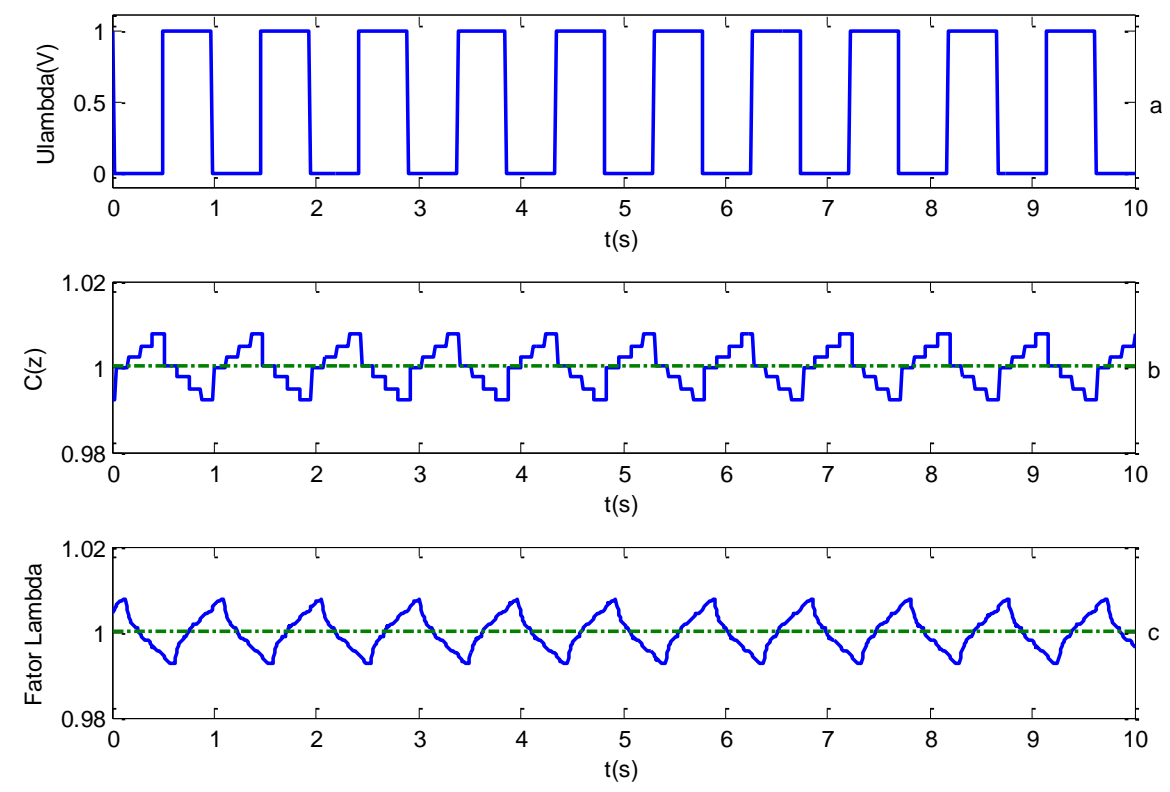

Figura 9 - Resposta do sistema em MF (malha fechada). (a) Tensão da sonda on-off. (b) Sinal do controle. (c) Lambda.

A frequência de oscilação do sinal da sonda lambda ficou em aproximadamente $1 \mathrm{~Hz}$. O controlador (9b) dá uma resposta do tipo jump-back. A resposta do sistema, apresentada na figura 9c, varia constantemente ao redor do valor estequiométrico. Apesar disso, essa resposta oscilatória tem média 1, e é exatamente o valor médio de lambda o parâmetro mais importante na resposta deste controle, pois ele afeta diretamente a eficiência do conversor catalítico e deve ficar dentro da janela de conversão do catalisador.

Após as simulações o controlador foi habilitado no motor do veículo. O teste foi realizado com uma rotação de 1200 RPM e sem carga. Assim que o controle em malha fechada foi habilitado, utilizando o compensador PI descrito anteriormente, o compensador começou a atuar para corrigir o erro e levar a mistura à condição estequiométrica. Como a mistura estava pobre $(\lambda>1)$, como mostram as figuras $10 \mathrm{a}$ e $10 \mathrm{c}$, o fator de multiplicação aumenta para corrigir a massa de combustível conforme a figura $10 \mathrm{~b}$. 

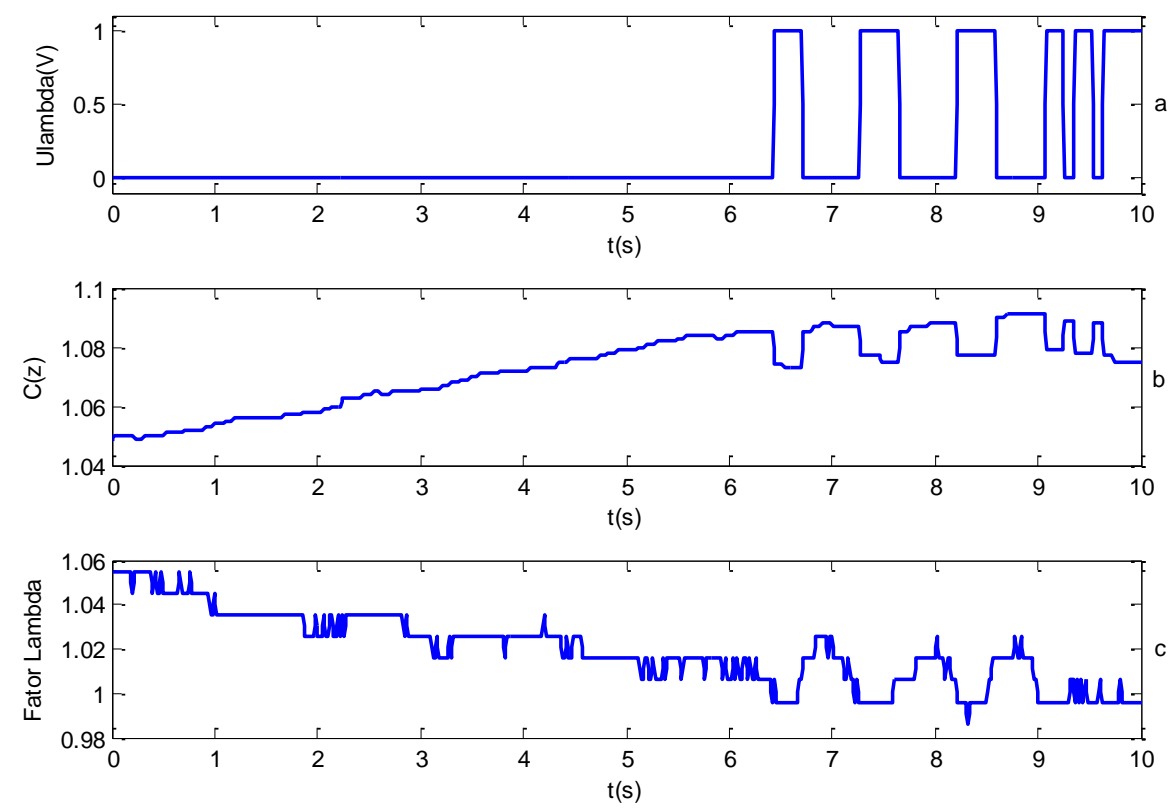

Figura 10 - Resposta dinâmica do sistema real em malha fechada. (a) Tensão da sonda on-off.

(b) Sinal do controle. (c) Lambda.

Assim que o ponto estequiométrico é atingido (entre 6 e 7 segundos), a resposta do controlador passa a ter sua forma oscilatória característica. A resposta do sistema em malha fechada, mostrada na figura 11, apresentou um valor de lambda com variação de apenas $\pm 2 \%$ em relação ao estequiométrico e obteve média em 1,002, conseguindo manter a média muito próxima do valor estequiométrico com erro de apenas $0,2 \%$ e assim ficar dentro da janela limite de $\pm 0,5 \%$ de máxima eficiência do conversor catalítico, comprovando a eficiência deste controlador.
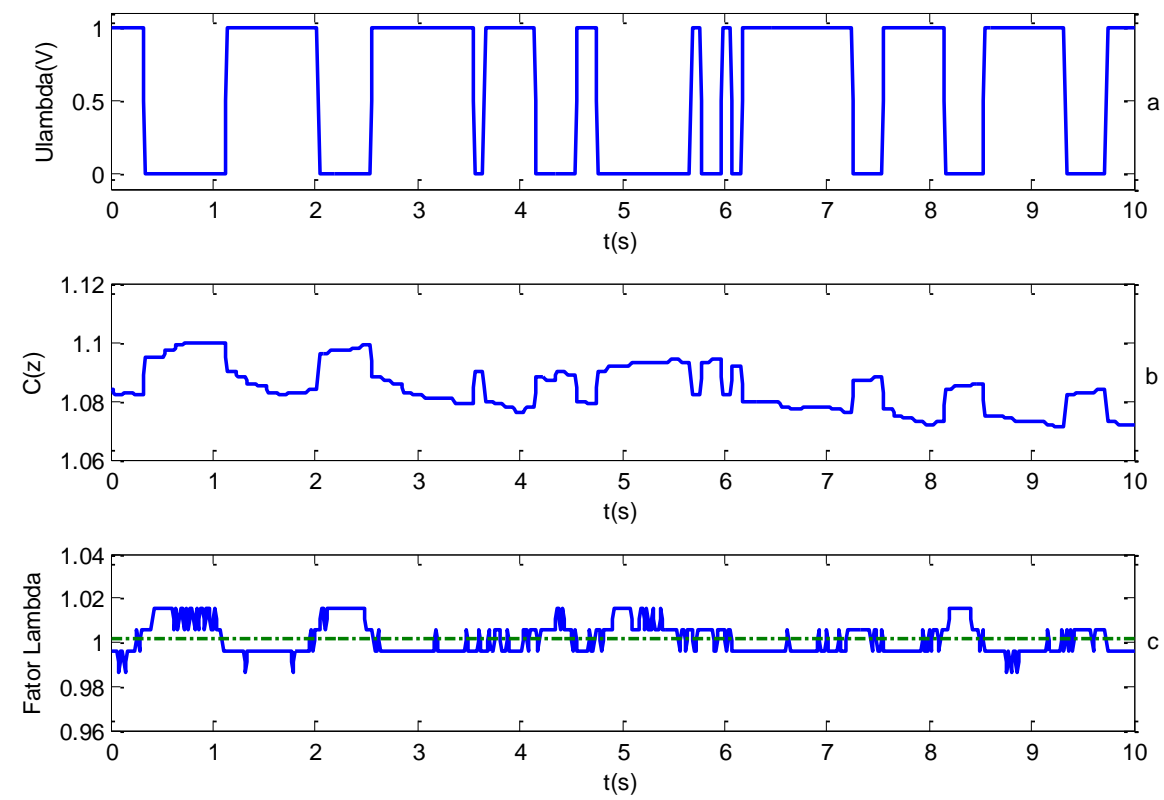

Figura 11 - Resposta do sistema real em malha fechada. (a) Tensão da sonda on-off. (b) Sinal do controle. (c) Lambda. 
A utilização do sensor lambda on-off como realimentação faz com que a resposta dinâmica do sistema seja lenta, devido ao baixo valor dos ganhos proporcional e integral que devem ser limitados para não desestabilizar o sistema. Um sensor de banda larga como realimentação proporcionaria a utilização de ganhos mais elevados, melhorando a resposta dinâmica do sistema, além de permitir o controle para valores de lambda diferente de 1.

\subsection{Projeto utilizando a sonda lambda de banda larga}

O sistema em malha fechada, utilizando como realimentação a sonda lambda de banda larga, segue o mesmo princípio do on-off, sendo que agora o sinal do sensor não é apenas binário (rico ou pobre), e sim um sinal de característica linear. A realimentação é comparada com uma referência desejada (não necessariamente de lambda igual a 1 como é com a sonda on-off) e então entra em um compensador para levar o sistema à referência desejada. A figura 12 mostra o diagrama de blocos deste sistema:

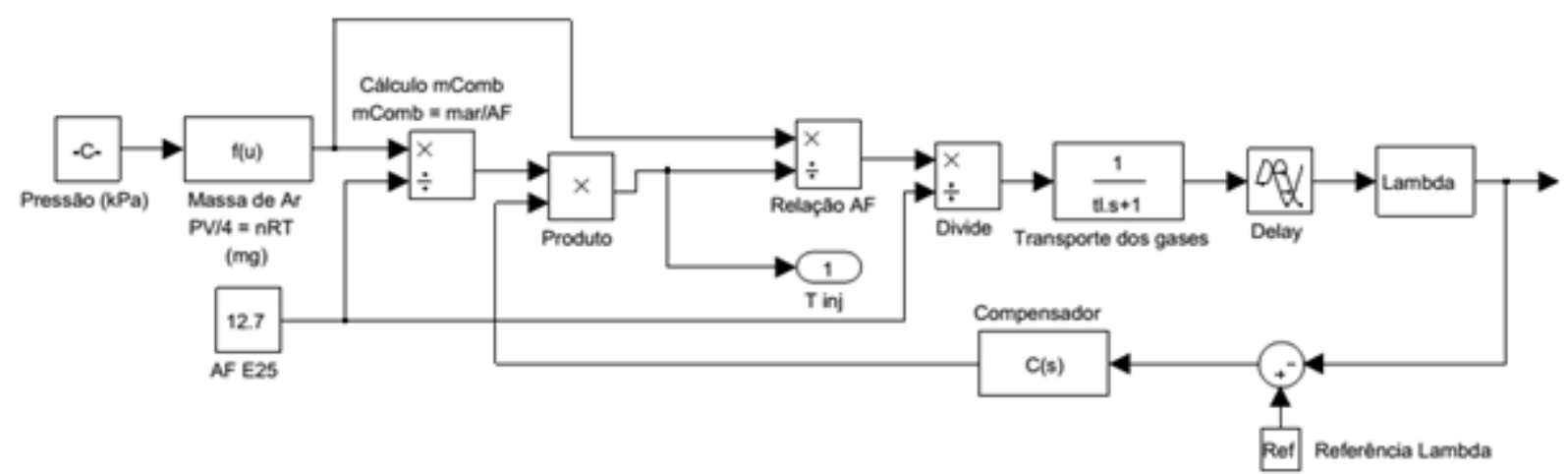

Figura 12 - Diagrama de blocos do sistema em malha fechada com realimentação pela sonda lambda de banda larga.

O compensador utilizado também é do tipo proporcional-integral:

$$
C(s)=1+\left(P+I \frac{1}{s}\right) e(t)
$$

Como o controlador será implementado em um microcontrolador, o controlador foi transformado para a forma discreta seguindo a equação (6). Como o problema passou a ser um sistema linear, os ganhos do compensador foram calculados usando o método da síntese direta [20, 21]. Este método permite o cálculo dos ganhos proporcional e integral com base nas características do sistema, conforme as equações (10) e (11):

$$
\begin{aligned}
& \mathrm{P}=\frac{1}{\mathrm{k}} \frac{\mathrm{tl}}{\text { delay }+\mathrm{t}_{\mathrm{c}}} \\
& \mathrm{I}=\frac{\mathrm{P}}{\mathrm{tl}}
\end{aligned}
$$

onde tl é o tempo de resposta do sistema, delay é o atraso e k é o ganho. Pelo modelo definido anteriormente, $\mathrm{k}$ é igual a 1 , e o tempo de resposta varia com a velocidade do motor conforme a equação (2) e o delay é aproximado pelo dobro do tempo de resposta. $\mathrm{O}$ parâmetro $\mathrm{t}_{\mathrm{c}}$ é o tempo de resposta desejado para o sistema. 
Após a definição do controlador, foram realizadas algumas simulações para a avaliação da resposta deste controlador com os ganhos obtidos pelo método descrito anteriormente. Na primeira simulação foi aplicado um degrau na referência de lambda de amplitude 1,1, e os ganhos do sistema foram calculados para um tempo de resposta $t_{c} 1$ segundo. A figura $13 \mathrm{a}$ mostra o sinal do controle PI e a figura $13 \mathrm{~b}$ mostra o degrau na referência (em $\mathrm{t}=1 \mathrm{~s})$, e a resposta do sistema com característica superamortecida, onde é possível observar que o tempo de resposta foi alcançado em 1 segundo definido anteriormente (em t=2s, lambda em $63 \%$ do degrau de referência). Após a acomodação do sinal, o erro de acompanhamento da referência é de 0 . Variando $t_{c}$ para 2 e 4 segundos, foi obtido a mesma resposta porém com os tempos exatamente iguais aos definidos.
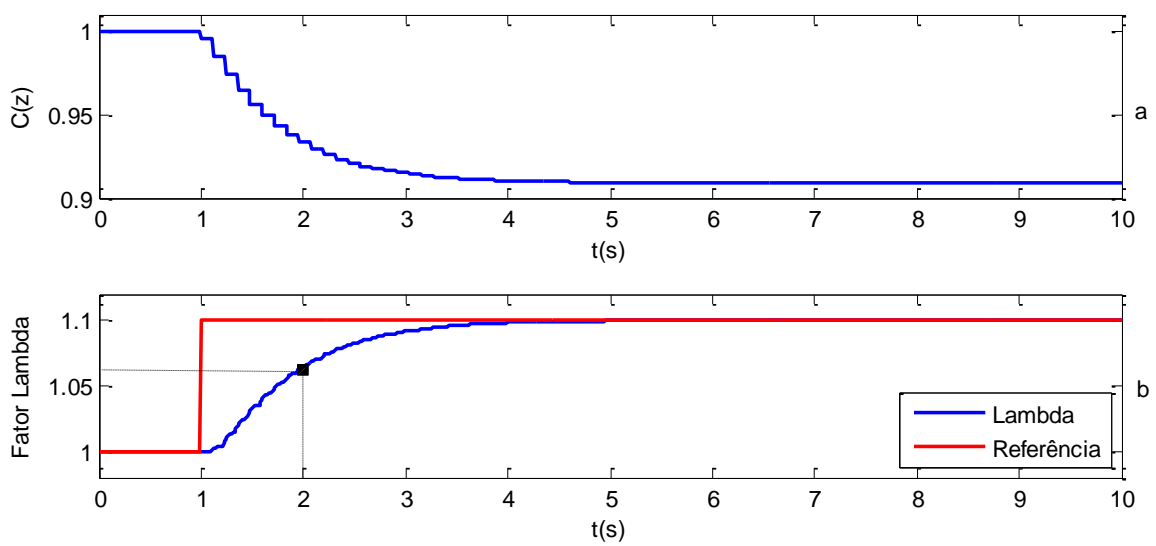

Figura 13 - Resposta simulada do sistema em malha fechada. (a) Sinal do controle. (b) Lambda.

Para os testes do sistema em malha fechada no veículo foram definidas algumas condições de funcionamento para a avaliação do controlador projetado. As condições para avaliação do erro de estado estacionário são:

- $\mathrm{t}_{\mathrm{c}} 1,2$ e 4 segundos; e

- Rotação do motor em 900 (marcha lenta), 1200, 2000 e 3000 RPM.

O objetivo é manter lambda o mais próximo possível de 1, para que a média esteja dentro da janela de $0,5 \%$ de conversão ideal do catalisador. A figura 14 mostra o resultado do sistema em malha fechada para o tempo de resposta de 1 segundo na rotação de marcha lenta, onde a média de lambda ficou em apenas 1,002. 

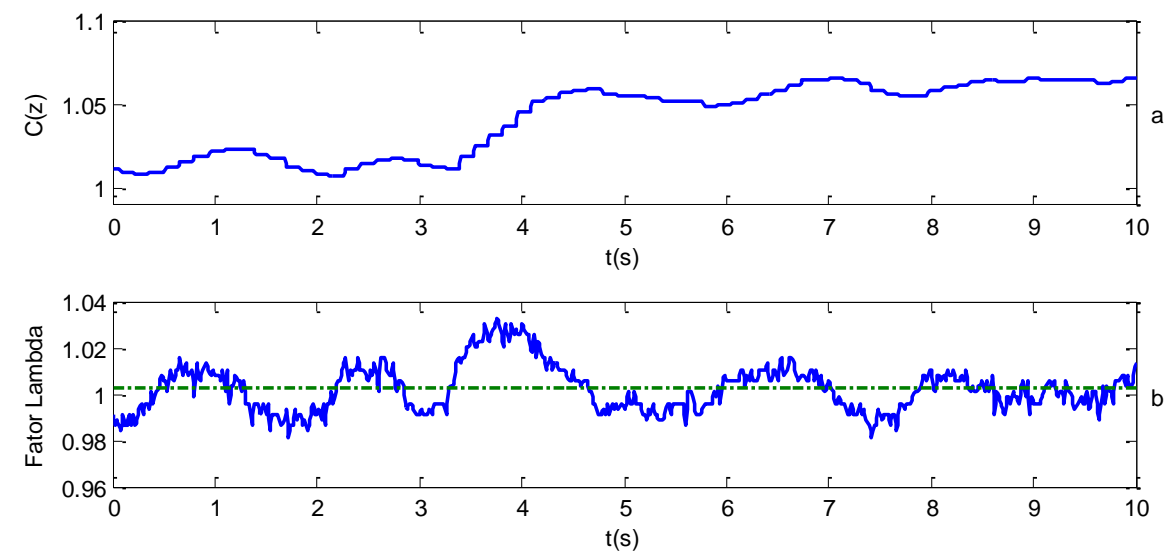

Figura 14 - Resposta do sistema real em MF. (a) Sinal do controle. (b) Lambda.

A tabela 1 resume os resultados do sistema para as outras condições citadas anteriormente. No sistema real, é importante realizar a análise da rotação do motor, pois uma variação da rotação muito grande indica que o sistema está tendendo à instabilidade $[21,22]$.

Tabela 1 - Comparativo da resposta do sistema para diferentes valores de $t_{c}$ e diferentes rotações.

\begin{tabular}{|c|c|c|c|c|}
\hline $\begin{array}{c}\text { Tempo de } \\
\text { resposta } t_{c}(s)\end{array}$ & $\begin{array}{c}\text { Rotação } \\
\text { (RPM) }\end{array}$ & $\begin{array}{c}\text { Lambda } \\
\text { médio }\end{array}$ & $\begin{array}{c}\text { Erro lambda } \\
(\%)\end{array}$ & $\begin{array}{c}\text { Variação } \\
\text { rotação (RPM) }\end{array}$ \\
\hline \multirow{4}{*}{1} & 900 & 1,002 & 0,2 & 100 \\
\hline & 1200 & 1,0013 & 0,13 & 40 \\
\hline & 2000 & 0,9953 & 0,47 & 89 \\
\hline & 3000 & 0,9955 & 0,45 & 93 \\
\hline \multirow{4}{*}{2} & 900 & 1,0017 & 0,17 & 64 \\
\hline & 1200 & 1,0006 & 0,06 & 86 \\
\hline & 2000 & 0,9996 & 0,04 & 35 \\
\hline & 3000 & 0,9956 & 0,44 & 61 \\
\hline \multirow{4}{*}{4} & 900 & 1,0036 & 0,36 & 54 \\
\hline & 1200 & 0,9983 & 0,17 & 66 \\
\hline & 2000 & 0,9983 & 0,17 & 33 \\
\hline & 3000 & 0,9951 & 0,49 & 76 \\
\hline
\end{tabular}

Analisando estes resultados, é possível observar que em rotação de marcha lenta, o valor médio de lambda é maior do que nas rotações de 1200 e 2000, e depois volta a aumentar na faixa de 3000 RPM, isto ocorre porque este aumento nas rotações também causa um aumento na frequência de variação de lambda. Em relação aos tempos de resposta, o que obteve os menores erros de lambda nas faixas de rotação foi o de 2 segundos. Olhando para a variação da rotação, percebe-se que à medida que o tempo de resposta foi aumentando, a variação diminuiu, que se deve ao fato de que com tempos de resposta maior, os ganhos proporcional e integral do controlador diminuem, assim lambda tende a ter menor variação e, consequentemente, menor variação na velocidade do motor. Apesar das particularidades, o controlador com os três valores de $t_{c}$ conseguiu manter o valor médio de lambda com valor menor que $0,5 \%$. 
Para avaliar a dinâmica, foram realizados testes com degrau na referência de lambda com as seguintes características:

- Degrau lambda de 0,8, 1,05, e 1,2 no instante 0s;

- Tempos de resposta 1, 2 e 4 segundos;

- Rotação fixa em 1200 em RPM.

A figura 15 apresenta a resposta do sistema para um degrau de lambda de 1 para 0,8 com tempo de resposta de 1 segundo.
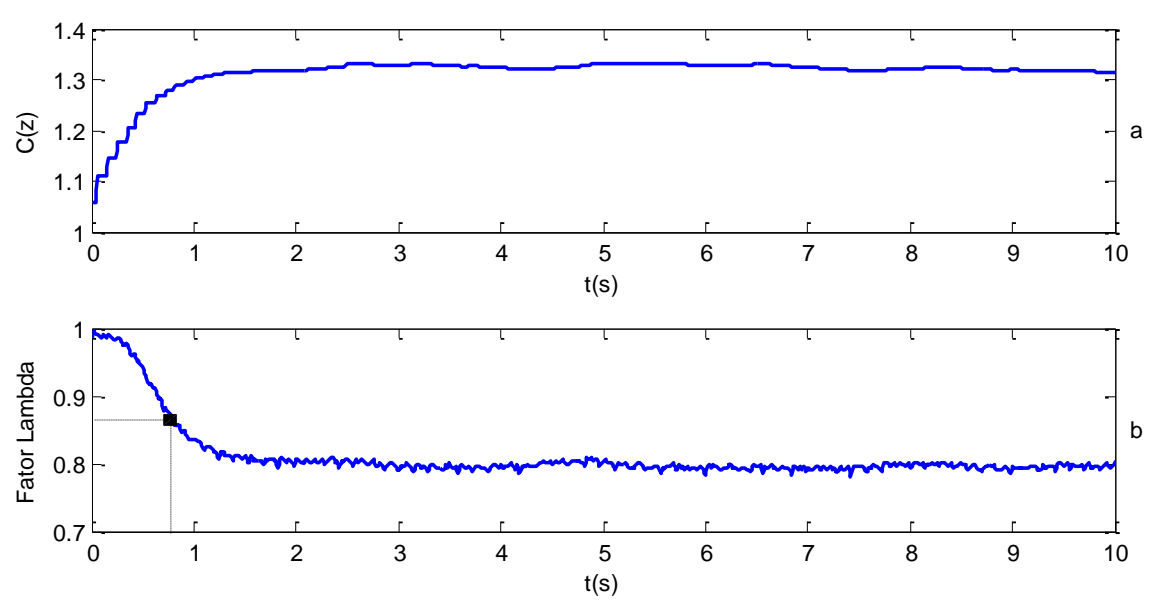

Figura 15 - Resposta do sistema em MF para entrada em degrau. (a) Sinal do controle. (b) Lambda.

A resposta teve uma característica superamortecida, assim como nas simulações, porém, o tempo de resposta obtido foi de aproximadamente $0,75 \mathrm{~s}$, sendo $0,25 \mathrm{~s}$ mais rápido do que o definido de $1 \mathrm{~s}$. Para $\mathrm{t}_{\mathrm{c}}$ de 2 segundos, a resposta foi mais rápida em $0,4 \mathrm{~s}(1,6 \mathrm{~s})$, e para $\mathrm{t}_{\mathrm{c}}$ de 4 segundos a resposta foi 0,75 mais rápida $(3,25 \mathrm{~s})$.

Introduzindo um degrau indo de lambda igual a 1 para a região pobre fez com que o sistema apresentasse uma resposta bastante sensível à variação de lambda chegando até a instabilizar o sistema, como mostra a figura $16 \mathrm{em}$ que foi introduzido um degrau de 1 para 1,2 com $\mathrm{t}_{\mathrm{c}}$ igual a $1 \mathrm{~s}$.
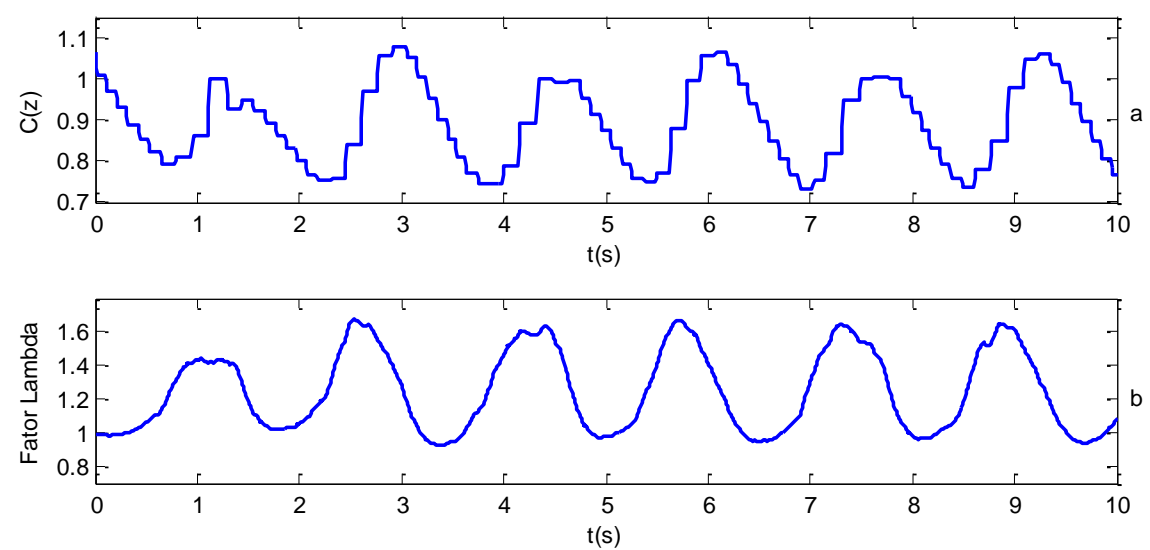

Figura 16 - Resposta instável ao degrau para a região de mistura pobre. 
Esse comportamento se deve ao fato de que como a mistura está empobrecendo, a velocidade de rotação do motor tende a cair, e então há um conflito entre o controle em malha aberta que tenta aumentar a rotação para não deixar o motor morrer e o controle em malha fechada que tenta empobrecer a mistura para chegar à referência de 1,2 .

Aumentando o tempo de resposta $t_{c}$ até $4 \mathrm{~s}$ ainda não é o suficiente para alcançar a referência de 1,2s sem causar alguma instabilidade. Foi definindo então um limite máximo de 1,05 para a referência de lambda pobre, a fim de não causar instabilidades. A figura 17 mostra que a resposta do sistema com um valor de $t_{c}$ de $1 \mathrm{~s}$ para esta entrada degrau teve uma característica sub-amortecida.
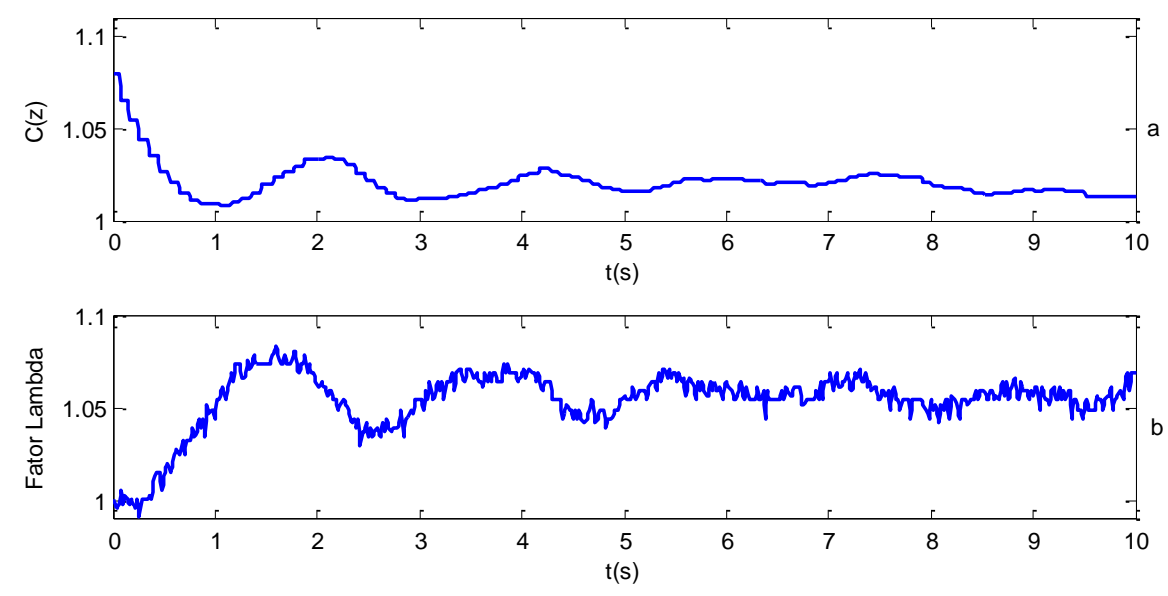

Figura 17 - Resposta sub-amortecida do sistema em malha fechada.

O tempo de resposta obtido foi pouco mais $0,3 \mathrm{~s}$ mais rápido do que o definido. Também houve um sobressinal de mais de $50 \%$ e o tempo de acomodação foi de aproximadamente $7 \mathrm{~s}$. Para $\mathrm{t}_{\mathrm{c}}=2 \mathrm{~s}$ a resposta também foi sub-amortecida com tempo de resposta $1 \mathrm{~s}$ mais rápido, porém o sobressinal diminuiu para cerca de $25 \%$ e o tempo de acomodação para $5 \mathrm{~s}$. Aumentando $t_{c}$ para $4 \mathrm{~s}$ fez com que a resposta apresentasse característica superamortecida e o tempo de resposta obtido foi de $2 \mathrm{~s}$, metade do tempo definido em $t_{c}$.

Estes resultados mostram que o sistema se comporta de maneira diferente na região de lambda pobre, com um tempo de resposta aproximadamente duas vezes maior do que na região de lambda rico. Esse fato acontece devido a uma diminuição da potência com a mistura pobre.

Comparando os resultados dos testes executados, foi possível observar que o melhor valor de $t_{c}$ é de $2 \mathrm{~s}$, que obteve os menores erros e menores variações nos testes de erro estacionário e ainda apresentou resultados dinâmicos satisfatórios. Entretanto, o ideal seria tornar $t_{c}$ em um parâmetro de calibração, onde fosse possível definir o valor que deve trazer o melhor compromisso entre desempenho e estabilidade em cada uma das regiões de operação do motor.

Vale ressaltar ainda que o uso da sonda lambda banda larga traz mais flexibilidade que o uso da sonda de banda estreita ao controle do motor por permitir diferentes valores de lambda que não o estequiométrico, além de apresentar menores erros de referência. 


\section{CONCLUSÃO}

Este trabalho desenvolveu um sistema de controle da mistura ar/combustível em uma unidade de gerenciamento eletrônico de motores à combustão interna. Para o desenvolvimento do sistema, foi utilizado um modelo simples e foi implementado um sistema de controle PI, e que apresentou resultados bastante satisfatórios, onde foi possível manter lambda dentro do limite estabelecido.

Com o modelo, foi possível simular o sistema em MATLAB/Simulink ${ }^{\circledR}$ e analisar a reposta do sistema em diversas condições. Posteriormente, foi introduzido o controle em malha fechada por realimentação feedforward com um compensador do tipo Proporcional Integral. A resposta do sistema utilizando como realimentação a sonda lambda on-off com este tipo de controle foi satisfatória e alcançou o resultado esperado nas simulações, levando a reposta média do sistema a ficar dentro da janela considerada aceitável para o correto funcionamento do conversor catalítico. Com a realimentação sendo feita pela sonda de banda larga, os resultados foram melhores dos que os obtidos com a realimentação pela sonda de banda estreita e atingiram os valores esperados que foram estabelecidos como limite.

Após as simulações, o controlador com a sonda on-off foi implementado na unidade de gerenciamento. Os testes foram realizados com condições fixas de aceleração e ponto de ignição para avaliar o funcionamento do controle desenvolvido. Com o sistema em malha fechada, o controlador atuou na massa de combustível para atingir o ponto estequiométrico e, então, entrou em seu regime permanente, conhecido como jump-back. Os resultados mostraram que com este controle foi possível atingir a meta e fazer com que o fator lambda médio ficasse dentro da janela aceitável e também com garantia de estabilidade do sistema.

Os resultados dos testes com a sonda lambda de banda larga mostraram maior flexibilidade na implementação em relação ao da sonda on-off, por ser possível utilizar como referência valores de lambda que não o estequiométrico e pela introdução de um parâmetro que pode ser definido pelo projetista e que se deve tornar um parâmetro de calibração. Além disso, a resposta conseguiu atingir a meta de lambda médio na análise do erro estacionário e obteve desempenho satisfatório nos testes dinâmicos.

\section{REFERÊNCIAS}

[1] A. G. Ulsoy, H. Peng e M. Çakmakci, Automotive Control Systems, $1^{\text {a }}$ ed., Nova York: Cambridge University Press, 2012.

[2] J.-C. Ruiz, P. Gil, P. Yuste e D. de-Andrés, "Dependability Benchmark of Automotive Engine Control Systems," em Dependability Benchmarking for Computer Systems, Wiley-IEEE Computer Society Press, 2008, pp. 111-140.

[3] J. Yu e B. M. Wilamowski, "Recent Advances in In-vehicle embedded systems," IEEE Industrial Electronics Society - IECON 2011, pp. 4623-4625, 2011.

[4] S. Karagiorgis, K. Glover e N. Collings, "Control Challenges in Automotive Engine Management," European Journal of Control. Vol 13. no 2-3, pp. 92-104, Janeiro 2007.

[5] H. CHEN, X. GONG, Y.-F. HU, Q.-F. LIU, B.-Z. GAO e H.-Y. GUO, “Automotive Control: the State of the Art and Perspective," Acta Automatica Sinica. Vol 39. $n^{\circ} 4$, pp. 322-346, Abril 2013. 
[6] Zhang H., H. R. Karimi, X. Zhang e J. Wang, "Advanced Control and Optimization with Applications to Complex Automotive Systems," Mathematical Problems in Engineering. Vol 2014, pp. 1-3, 2014.

[7] M. Gleirscher, A. Vogelsang e S. Fuhrmann, "A Model-Based Approach to Innovation Management of Automotive Control Systems," IEEE 8th International Workshop on Software Product Management, pp. 1-10, 2014.

[8] L. Guzzella e C. H. Onder, Introduction to Modeling and Control of Internal Combustion Engine Systems, 2a ed., Zurique: Springer-Verlag, 2010.

[9] J. R. Wagner, D. M. Dawson e L. Zeyu, "Nonlinear Air-to-Fuel Ratio and Engine Speed Control for Hybrid Vehicles," IEEE Transactions on Vehicular Technology. Vol 52. $n^{o}$ 1, pp. 184-195, Janeiro 2003.

[10] M. Balenovic, "Modeling and Model-Based Control of a Three-Way Catalytic Converter," Eindhoven, 2002.

[11] J. B. Heywood, Internal Combustion Engine Fundamentals, $1^{\text {a }}$ ed., vol. 1, A. Duffy e J. M. Morriss, Eds., Nova Iorque: McGraw-Hill, 1988.

[12] W. B. Ribbens, Understanding Automotive Eletronics, $5^{\text {a }}$ ed., Woburn, Massachusetts: Butterworth-Heinemann, 1998.

[13] T. Denton, Automobile Electrical and Electronic Systems, $3^{\text {a }}$ ed., Londres: Elsevier Butterworth-Heinemann, 2004.

[14] W. W. Pulkrabek, Engineering Fundamentals of the Internal Combustion Engine, $2^{\mathrm{a}}$ ed., vol. 1, Platteville: Prentice Hall, 2003.

[15] U. Kiencke e L. Nielsen, Automotive Control Systems, $2^{a}$ ed., Berlim: Springer, 2005.

[16] R. J. Farrauto e R. M. Heck, "Catalytic Converters: State of the Art and Perspectives," Catalysis Today - 51, pp. 351-360, 1999.

[17] Zhang Y., R. W. Cattrall, I. D. McKelvie e S. D. Kolev, "Gold, an alternative to platinum group metals in automobile catalytic converters," Gold Bulletin. Vol 44. $n^{\circ} 3$, pp. $145-$ 153, Agosto 2011.

[18] B. C. F. PEREIRA, "Unidade de Gerenciamento Eletrônico de um Motor Volkswagen 2.0L: Projeto Otto II.," São Paulo, 2013.

[19] H. Peng, G. T.-C. Chiu e T.-C. Tsao, "Digital Control of Discrete Systems. Chap 6 Design of Discrete Time Controller," Boulder, 2008.

[20] D. E. Seborg, T. F. Edgar e D. A. Mellichamp, Process Dynamics and Control, $2^{\mathrm{a}}$ ed., Santa Barbara: Wiley, 2004.

[21] G. T. Braga, "Uma Contribuição ao Controle de Motores de Combustão Interna de Ignição por Centelha na Condição de Marcha Lenta," Belo Horizonte, 2007.

[22] F. J. P. PUJATTI, "Desenvolvimento de um Sistema de Gerenciamento Eletrônico para Motores de Ignição por Centelha," Belo Horizonte, 2007. 